\title{
THE CONCEPT OF FORCE AS A CONSTITUTIVE ELEMENT OF UNDERSTANDING THE WORLD
}

\author{
KEES KLAASSEN \\ Utrecht University, The Netherlands
}

\begin{abstract}
This paper concerns interpretation and constitutive elements of understanding the world, both of which are treated in relation to the concept of force. Studies are criticized in which students' conceptions are formulated, without further clarification, in terms of the word 'force'. From such reports it can neither be concluded what students believe nor how their beliefs relate to science. Instead, reasons or criteria for applying 'force' need to be made explicit. Those reasons concern the effects that forces produce, namely deviations from an influence-free state; they also concern their sources, as made explicit in laws from which, for a given situation, the forces acting in it can be derived. The general concept of force, thus associated with the two-tier explanatory strategy of specifying (1) influence-free states and (2) force laws to account for deviations from those states, is a constitutive element of understanding the world. Within the constraints set by this explanatory strategy, the concept of force can still be variously applied, both in everyday and in scientific explanations. The differences between these various applications are partly anchored in distinct explanatory interests.
\end{abstract}

\section{INTRODUCTION}

There is quite some consensus about one cause of the ubiquitous finding that students do not learn as much as was hoped for. A student entering a science class is not a tabula rasa but already has conceptions: domain specific beliefs; more general ones concerning the nature of science, epistemology, or ontology; and attitudes other than beliefs, such as motives, interests, and affects. Opinions begin to diverge concerning the status of students' prior conceptions and how to properly take them into account. Some claim that the prior conceptions 'are often in stark contrast to the science conceptions to be learned' and that 'major restructuring of the already existing knowledge is necessary' (Duit, 1999). Others argue that this view 'overemphasizes the discontinuity between students and expert scientists' and think of students' prior conceptions as 'resources for cognitive growth' (Smith et al., 1993).

One major focus of this paper is a question that ought to precede the further question if - or in what sense - students' conceptions are impedient or expedient to their learning of science. This question is: what is the content of their conceptions? I raise this simple question, because I have doubts about the validity of a lot of

(C) 2005 Springer. Printed in the Netherlands. 
research on students' ideas. The answer to this question, with respect to the concept of force, introduces the other major focus of this paper: a discussion of the relations between common sense and science in terms of constitutive elements of understanding the world.

\section{THE PROBLEM OF INTERPRETATION}

In early studies on children's pre-instructional theories of motion (Halloun \& Hestenes, 1985; Gunstone \& Watts, 1985), it is reported that children seem to operate with basic intuitive rules such as:

Sustained motion needs a continuous force.

If an object is in motion, it has a force in the direction of its motion.

If there is no continuous supply of force, the force of an object wears out.

Forces can be imparted by agents and transferred from one object to another.

Of course, children or lay people do not always frame their ideas in these exact words. But it is a small step from 'If he wanted to keep moving along he would have to keep pushing' (an example of what a child actually said, cf. Gunstone \& Watts) to 'Sustained motion needs a continuous force'. So, it is plausible to assume that the child would have assented to the latter sentence. If children and lay people can be said to hold the intuitive theory in this sense, what follows?

According to many researchers the intuitive theory is 'at variance with the principles of Newtonian mechanics' (McCloskey, 1983). I agree that 'Sustained motion needs a continuous force' seems to be contradictory to Newton's first law, and that 'to have a force' is meaningless in Newtonian mechanics. But does it follow that the intuitive theory contradicts Newtonian mechanics? I think not. Consider:

\section{S. Sustained motion needs a continuous force.}

Children and lay people would assent to S, while Newton would dissent from it. This only implies they have contradictory beliefs, however, if all parties understand $\mathrm{S}$ in the same way, i.e. if there is identity of meaning. But does students' preinstructional concept of force, in particular, match the Newtonian one? Most researchers probably hold that it does not. My criticism begins when it is left unsettled what, then, students' pre-instructional concept of force is, for this also leaves unsettled what children and lay people believe when they assent to S. Only after all this is settled, can one ask whether their belief contradicts any of Newton's beliefs. The same criticism may apply to researchers who hold that at least some of students' conceptions are in agreement with science. In the case of a spring that one holds compressed, both a student and a physicist assent to 'The spring exerts a force on the hand'; and in the case of a book lying on a table, only the physicist assents to 'The table exerts a force on the book'. On this basis nothing can be concluded, as yet, about beliefs. Neither does it follow that in the latter case student and physicist have contrary beliefs, nor that in the former their beliefs are in agreement (cf. 
Klaassen \& Lijnse, 1996, for further discussion, including an evaluation of the bridging strategy of Clement et al., 1989).

The above exemplifies two related issues (cf. Davidson, 2001, essays 9 to 12). First, the interdependence of belief and meaning: what someone believes when she assents to some sentence depends on what the sentence means for her. Second, the associated problem of interpretation: if we only know which sentences someone assents to, and we cannot assume identity of meaning, then how are we to find out what her sentences mean and what she believes? My methodological criticism of a lot of research into children's thinking is that this problem of interpretation, despite quite common implicit recognition, is hardly ever explicitly mentioned, let alone properly solved. Reports in which intuitive theories are formulated, without further clarification, in terms that are also in use in science, cannot be expected to have solved the problem.

\section{TOWARD A SOLUTION OF THE PROBLEM OF INTERPRETATION}

In this section I try to arrive at a solution of the problem of interpretation with respect to the concept of force, by drawing on studies also critical of mainstream research on students' conceptions.

\section{Avoiding the word 'force'}

In order to block associations with a physicist's use of the word 'force', a useful initial strategy is to avoid it. Bliss \& Ogborn (1993), for example, formulate a commonsense theory of motion in such terms as 'support' and 'effort'. Some elements of this theory are:

- If an object is supported it does not fall. If it is not supported it falls, until it is once more supported. Falling is a natural motion. One need not look for a cause for it to continue, only for a continued lack of support.

- To support something needs strength or effort. If the strength of a support is not enough, it may break. If the strength is enough the support takes the weight of the thing it supports.

DiSessa (1993) uses such terms as 'agent', 'result' and 'effort' in formulating his phenomenological primitives, e.g. Ohm's p-prim:

An agent exerts some effort in order to achieve a result through some resistance. Increased effort begets increased result. Increased resistance begets reduced result.

When I read what children say about familiar situations in which something moves, usually after it has been kicked, pushed, thrown, etc., I think I understand perfectly well what they are trying to say. When riding my bike I have to keep pushing to keep moving; the harder I throw something, the farther it gets, and so on. Put in somewhat more general terms, some basic intuitive rules can be formulated by which all of us operate (cf. Klaassen, 1995, section 2.2.3), for example: 
To keep things in motion, one has to keep making an effort, otherwise they will come to a stop.

- The motion of an object can cause something to happen. Faster motion begets more effect.

Dekkers (1996, section 2.7) presents a table, with on the left the most significant generalized students' statements involving the word 'force' he culled from the literature; and on the right his attempts to understand those statements without using the word 'force'. Here is a sample of his four-page-long table:

\begin{tabular}{|l|l|}
\hline $\begin{array}{l}\text { If a body is not moving, there is no force } \\
\text { acting on it. If a body is moving, there is a } \\
\text { force acting on it in the direction of } \\
\text { motion. }\end{array}$ & $\begin{array}{l}\text { Being at rest is a natural state of an object. } \\
\text { Absence of motion does not require an } \\
\text { explanation. Motion does not spontaneously } \\
\text { start. Moving objects differ from stationary } \\
\text { objects, which requires an explanation. }\end{array}$ \\
\hline $\begin{array}{l}\text { Forces are present in static situations if an } \\
\text { event will happen, is about to happen, or } \\
\text { is prevented from happening. }\end{array}$ & $\begin{array}{l}\text { In some situations, the fact that nothing } \\
\text { happens (yet) is out of the ordinary and requires } \\
\text { an explanation. This is the case when it is } \\
\text { believed that something will happen, is about to } \\
\text { happen or prevented from happening. Properties } \\
\text { of the current situation explain what will produce } \\
\text { the later effect. }\end{array}$ \\
\hline
\end{tabular}

Without pretending to have now solved the problem of interpretation, the above attempts to avoid the word 'force' may already have cast doubt on the oftensupposed alternativeness of students' conceptions.

\section{Making explicit the circumstances in which students hold the concept of force applicable}

Another useful strategy in solving the problem of interpretation is also intuitively clear. If we are to find out what someone's reasons or criteria are for applying the concept of force, we can do no better than assume that whenever she believes her criteria are applicable, they are in fact applicable. That is, we must assume that she does not, as a rule, misapply her own criteria, however difficult she herself may find it to articulate them clearly. The above attempts to avoid the word 'force' suggest that in commonsense reasoning forces are involved in explanations of something that is 'out of the ordinary' or deviates from a 'natural state'. An object 'exerts a force' if it causes a deviation, 'has a force' if it has the potentiality to do so, and 'transfers a force' if the caused deviation is such that another object causes a further deviation or has acquired the potentiality to do so. Dekkers lists examples of what students may consider as 'out of the ordinary': deformation, deflection, (reduction of) motion, stress. He summarizes these as 'activity', and formulates as rules governing the commonsense concept of force: 'activity implies a force' and 'more activity implies more force'. DiSessa's characterization of some p-prims can also be understood as indications of the kinds of deviation for which people may feel an explanatory need in terms of forces: 'force as a mover', 'force as a deflector', 'force 
as a spinner'. DiSessa and Dekkers also mention examples of what students may consider as sources of forces: animate agents, engines, collisions, supports, springs.

\section{Capturing the essence of the concept of force}

By combining some of the suggestions mentioned above, we may try to capture the essence of the commonsense concept of force in the slogan 'force as a deviator from a natural state'. DiSessa plays with the thought that something like this might be a meta p-prim, but in the end he rejects it: 'many kinds of change need explanation but [...] there is no [fixed or] universal characterization of change [or of natural state, $\mathrm{KK}$ ] that covers the circumstances in which people feel the need, or not, to look for deeper causation.' So if 'force as a deviator from a natural state' is proposed as a solution to the problem of interpretation with respect to 'force', a problem of interpretation with respect to 'natural state' immediately surfaces. The latter problem is as difficult as the original one; in fact, they are the same.

Does this imply that we have to give up the attempt to capture the essence of the concept of force; and must we rest content with an exemplary list of the kinds of circumstance that may be considered as 'out of the ordinary', and thus as standing in need of explanation? Precisely this is the 'knowledge in pieces' view that diSessa argues for: the explanatory needs that people feel 'are distributed according to the kind of change; that is, they are embedded in the [phenomenological] primitives that connect to the particular circumstance.' Dekkers is undecided. On the one hand, he admits that his analysis 'does not yet provide an integrated, comprehensive theory for the common-sense concept of force'; on the other, he does 'not even claim that all of the students' views can be described in one comprehensive and coherent theory.'

I agree with diSessa that there is no single, all-purpose class containing all and only effects of forces, and the same goes for sources of forces. Nevertheless, I think diSessa's pieces can find their place in a coherent whole. What still needs to be made explicit is the conceptual pressure that governs the rightness of fit between source and effect. 'Force as a deviator from a state' only makes explicit that the concepts of force and state are mutually dependent; a further element still is to be found which governs their mutual application. In my view the notion of generality will do. Part of the reason for holding that in a particular situation there is a deviation effectuated by a force, is that there is reason to believe that in relevantly similar situations relevantly similar deviations would occur. I suggest capturing the essence of the concept of force by the following two-tier explanatory strategy:

a characterization of influence-free (force-free) states, checked by

a characterization of plausible lawlike statements (force-laws) in which deviations from those states are correlated with properties of the configurations in which those deviations occur.

This two-tier strategy makes explicit the intimate connection between interaction theory (the collection of relevant force laws) and the notion of state (cf. 
Friedman, 1983, section III.7). The strategy does not tell us what we ought to choose as forces, states, laws, etc. It only sets constraints on such choices. It offers an explanatory scheme into which the choices we make must fit. The scheme may need to be augmented with further basic elements, such as the semi-quantitative 'the more force, the more deviation' or a notion of laziness (inertia) to indicate that different bodies react differently to an applied force (the more inertia, the less deviation). DiSessa's p-prims can also find their place here.

\section{SPECIFIC APPLICATIONS OF THE CONCEPT OF FORCE AND THEIR INTERRELATIONS}

The general concept of force can still be applied in explanations in various specific ways. In this section I give examples of such specific applications and their interrelations.

Examples of specific applications of the general concept of force

The two-tier explanatory strategy indicated above can be seen at work in commonsense explanation of motion. In everyday life we take a strong interest in how to move objects from $A$ to $B$, or to move ourselves from $A$ to $B$ by means of some object. Within this context, it makes good sense to consider as influence-free the way in which the objects would move without our interference (stand still or gradually come to a stop), given that at the same time we happen to know enough generalizations, however crude or vague they may be, in which relevant deviations (setting in motion, keeping in motion, braking) are satisfactorily correlated to kinds of action we can perform. Given another goal, e.g. hitting a target with a projectile, another type of motion can be considered as influence-free, as long as this is checked by the availability of sufficient rules of thumb to account for relevant deviations from that type of motion. Many of the intuitive rules concerning motion are (related to) crude laws between kinds of action and kinds of deviation from a particular type of motion. Thus, a ragbag of specific applications of the concept of force can be seen to function in commonsense explanation, all of which are 'highly pragmatic not only in their conspicuous ties to action, but in their breezy disregard of the irrelevant or implausible' (Davidson, 1995).

The general concept of force can also be seen as structuring the Newtonian framework. It consists of (1) the specification of a kind of motion that is to count as a state (uniform rectilinear motion), and (2) interaction theory to account for all deviations from this type of motion in terms of force laws. Force laws, such as Newton's law of gravitation, are general statements that specify the forces objects exert on each other as a function of their total configuration (cf. Jammer, 1957, chapter 12). One can continue to take uniform rectilinear motion as a state, and here the conceptual pressure of generality is felt, as long as one is able to find plausible force laws to account for the deviations from it. 
Although Kepler himself has not systematically developed it, one can also specify a Keplerian style of explaining motion. It consists of (1) the specification of rest as the kind of motion that is to count as a state, and (2) interaction theory to account for deviations from rest. This is an application of the concept of force which differs from the Newtonian one. Keplerian net forces, just to name one difference, are of necessity always in the direction of motion. In order to account for planetary motion, Kepler imagined some kind of spokes emanating from the sun and pushing the planets along their orbits as the sun rotates about its axis (cf. Jammer, 1957, chapter 5). It is possible to make Kepler's idea precise and to formulate more or less plausible Keplerian force laws, which lead to the same predictions of planetary motion as within the Newtonian framework on the basis of a gravitational influence directed to the sun.

Relations between the various specific applications of the concept of force One aspect of the relation between the various specific applications of the concept of force is, of course, that they are specific applications of the same general concept. In all cases, the basic criteria for identifying forces are the same. In the circumstances under which the motion of an object deviates in some relevant way from the assumed influence-free motion, one will search for recurring configurations with which these deviations can be satisfactorily correlated. Such shared basic criteria still allow for different specific criteria, corresponding to the kind of motion considered as influence-free, in combination with why one needs an explanation and, given this purpose, with what one thinks can be explained by means of appropriate laws. In the same way, the shared basic explanatory strategy still allows for different specific explanations. Consider the question why one has to keep pedalling in order to keep speed on a bicycle. The specific commonsense explanation is straightforward. Keeping speed is a deviation from what, for the everyday purpose of moving oneself from $A$ to $B$ by means of some object, can plausibly be assumed as influence-free motion (stand still or gradually come to a stop), and according to the intuitive rules, a continuous effort by an agent can account for that kind of deviation. The specific explanation within Newtonian mechanics is more involved. Under normal terrestrial conditions, a moving bicycle comes to a stop. This kind of deviation from the Newtonian influence-free motion (uniform and rectilinear) can under normal terrestrial conditions be correlated with sources of opposing frictional forces. So to keep a body in motion one somehow has to make it the case that there is also a forward force. If this forward force balances the frictional forces, such that there is no net force, the result is uniform rectilinear motion.

Whereas in common sense there is no need for uniform application of the concept of force, things stand differently in Newtonian mechanics, when it is pursued in a frame of mind in which we want to understand things 'whether or not we can control them, and whether or not such knowledge will serve our mundane needs' (Davidson, 1995). In that frame of mind, explanation of motion, though it may answer to various interests, in itself is not relative to any interests. Every 
deviation from uniform rectilinear motion, whether it is of practical interest or not, ultimately has to be accounted for by means of exceptionless force laws. Such differences with respect to purpose, interest, and what is considered relevant, form another aspect of the relation between common sense and Newtonian mechanics. Due to rather disparate explanatory interests, there is no tension between Newtonian and commonsense explanation.

Within one and the same theoretical mood, different specific applications of the concept of force can still be tried, as illustrated by the Keplerian and Newtonian schemes. Within each scheme, deviations from the assumed influence-free motion provide motives to construct a theory that succeeds in accounting for the deviations; but because there are no guarantees that one will be able to do so, a rivalry arises between the two schemes. Their relative merits must be evaluated in the light of a shared commitment to the usual epistemic virtues associated with their fundamental aspirations, such as those of strict empirical adequacy and unification (cf. Nagel, 1979, section 7.II, for further discussion of the status of laws of motion).

\section{Educational challenges}

In my view the analysis above contains useful suggestions concerning the kind of work that must be done to provide students with incentives and conceptual tools to bridge the gap from common sense to Newtonian mechanics (cf. Westra et al., 2003, for more details). Students will somehow have to be brought into the theoretical mood that suits a fundamental research type of practice. The general concept of force, if appropriately made explicit on the basis of commonsense explanations, can then serve as a general scheme to be further specified. The Keplerian specification with its associated assumption of rest as influence-free motion may especially appeal to students. If presented together with the Newtonian specification, students can try to construct, for both specific schemes, interaction theories that succeed in accounting for, say, planetary motion. What will be evident to them is that the force laws need to be empirically adequate in the sense that the predicted paths must match the actual paths as closely as possible. In a modelling process of fitting and adjusting parameters, they may thus, within both the Keplerian scheme and the Newtonian scheme, arrive at more or less adequate force laws. Such initial successes make it plausible to investigate whether for other cases than planetary motion it is also possible to find empirically adequate force laws within each of the two schemes. Thus, the schemes themselves can also come to be evaluated, and in an increasingly explicit way, in the light of the epistemic value of unification. In short, in a modelling process that both depends on and implements the general concept of force, and that is driven by epistemic values associated with a fundamental research type of practice, the Newtonian scheme can in the end be expected to fare better.

\section{CLOSING REMARKS}

In this section I suggest a broader application of an analysis like the one just given with respect to the concept of force. 


\section{Interpretation}

I have criticized studies on students' conceptions because of their neglect of the problem of interpretation. Johnson \& Gott (1996) have likewise given methodological criticism. They note that, contrary to the impression one might gain from the literature, finding out what a child thinks is not a straightforward task. It demands 'more than simply asking a child a few 'key' questions and then categorizing verbal responses according to forms of words'. They challenge the findings of some well-known research studies in terms of some plain methodological principles, which every researcher, when explicitly asked, would support. Nevertheless, it takes some effort to observe those principles, and in much research into children's thinking, they are insufficiently observed. Johnson \& Gott also suggest alternative interpretations which they try to support by further research; they also stimulate a re-evaluation of existing data.

Analyses like the one of Johnson \& Gott and those presented earlier in this paper (Bliss \& Ogborn, diSessa, Klaassen, Dekkers) suggest that the effect of a proper reinterpretation of studies into children's ideas is rather sobering. The outcome simply is that most of children's ideas are plain commonsense truths. This is part of the reason that it is difficult for me to maintain a genuine interest in studies into students' conceptions, and that they are only addressed here in order to point to methodological issues. The other part is based on a further analysis of interpretation as provided by the philosopher Davidson. He concludes that '[i]nterpretation requires us to see the mental lives of others as enough like our own in point of overall coherence and correctness to allow us to assign reasons to their acts, intentions, beliefs and other attitudes - in other words, to understand them. It requires us to see other agents as more or less rational creatures inhabiting a shared world that they conceive much as we do' (Davidson, 2000). If these interpretational maxims are correct, then their application to students' speech and action cannot result in anything else than that what they say and do is by and large coherent, correct, and to the point.

\section{Constitutive elements of understanding the world}

The general concept of force with its associated explanatory scheme is a special case of the so-called cause-law thesis. If two particular events are related as cause and effect ( $a$ caused $b$ ), there is a law (lawlike generalization) to the effect that 'all events similar to $a$ will be followed by events similar to $b$ '. We have reason to believe the singular causal statement only in so far as we have reason to believe there is such a law, and we may have good reason to believe there is such a law without knowing what the law is. Like the concept of force, the cause-law thesis offers an explanatory scheme. '[E]vents are changes that explain and require such explanations. This is not an empirical fact: nature doesn't care what we call a change, so we decide what counts as a change on the basis of what we want to explain, and what we think available as an explanation. In deciding what counts as a change we also decide what generalizations to count as lawlike. [...] if you can't explain it using one assumption of what counts as a change, adopt new categories 
that allow a redefinition of change' (Davidson, 1995). Ramberg suggests thinking of the cause-law thesis as a constitutive element of understanding the world. It expresses constraints on the application of such basic concepts as those of cause, change, state, kind, substance, and object. It thus forms a bond between common sense and the various sciences: no matter how distinct and diversely anchored in explanatory interests these various theoretical structures may be and remain, 'the constitutive interest in generality, the inherent susceptibility to law of their terms, marks them as [...] a part of the same general descriptive project' (Ramberg, 1999). Holding that the cause-law thesis is a constitutive element of understanding the world implies that our thoughts do not simply picture the world. It does not imply, however, that the world is of our own making, as (social) constructivists often seem to hold. Nor does it imply, that how we think the world is has got little to do with how the world is, as sceptics in their various ways maintain.

We do not, at least in any ordinary sense, choose the constitutive elements of understanding the world. They rather are ineluctable elements of what directs and explains our choices in understanding the world. So, I disagree with diSessa's (1993) suggestion that there is no reason to suppose 'that children cleanly and with high reliability encode the general principle that change needs a cause.' Rather, we must so interpret children that by and large they come out as abiding by this principle. This involves finding out what, in the context at hand, they take as changes, states, and laws. I can interpret some empirical studies on 'commonsense reasoning' in this sense (Whitelock, 1991; Gutierrez \& Ogborn, 1992). Other experimental work, however, such as an attempt to uncover basic dimensions of thought about the nature of entities (Mariani \& Ogborn, 1991), rather seems to try to draw some constitutive elements out of students. This seems to me misguided. Although students' understanding of the world also both implements and depends on the relevant constitutive elements, they simply are not the right kind of people to make those explicit. Obvious as the constitutive elements may sound once they are formulated, it takes the greatest minds to articulate them clearly and sharply. It is up to us as educationalists to explore whether and how they can be made educationally productive.

\section{REFERENCES}

Bliss, J. \& Ogborn, J. (1993). A common-sense theory of motion: issues of theory and methodology examined through a pilot study. In: P.J. Black \& A.M. Lucas (Eds.). Children's informal ideas in science. London: Routledge. 120-133.

Clement, J., Brown, D.E. \& Zietsman, A. (1989). Not all preconceptions are misconceptions: finding 'anchoring conceptions' for grounding instruction on students' intuitions. International journal of science education, (11). 554-565.

Davidson, D. (1995). Laws and cause. Dialectica, 49. 263-279.

Davidson, D. (2000). Objectivity and practical reason. In: E. Ullmann-Margalit (Ed.). Reasoning practically. Oxford: Oxford University Press. 17-26.

Davidson, D. (2001). Inquiries into truth and interpretation ( $2^{\text {nd }}$ edition). Oxford: Clarendon Press. 
Dekkers, P.J.J.M. (1996). Making productive use of student conceptions in physics education: development of the concept of force through practical work. Amsterdam: VU Huisdrukkerij.

DiSessa, A.A. (1993). Toward an epistemology of physics. Cognition and instruction, 10. 105-225.

Duit, R. (1999). Conceptual change approaches in science education. In: W. Schnotz, S. Vosniadou \& M. Carretero (Eds.). New perspectives on conceptual change. Amsterdam: Elsevier Science. 263-282.

Friedman, M. (1983). Foundations of space-time theories: relativistic physics and philosophy of science. Princeton: Princeton University Press.

Gunstone, R. \& Watts, M. (1985). Force and motion. In: R. Driver, E. Guesne \& A. Tiberghien (Eds.). Children's ideas in science. Milton Keynes: Open University Press. 85-104.

Gutierrez, R. \& Ogborn, J. (1992). A causal framework for analysing alternative conceptions. International journal of science education, 14. 201-220.

Halloun, I.A. \& Hestenes, D. (1985). Common sense concepts about motion. American journal of physics, 53. 1056-1065.

Jammer, M. (1957). Concepts of force: a study in the foundations of dynamics. Cambridge: Harvard University Press.

Johnson, P. \& Gott, R. (1996). Constructivism and evidence from children's ideas. Science education, 80. 561-577.

Klaassen, C.W.J.M. (1995). A problem-posing approach to teaching the topic of radioactivity. Utrecht: CD- $\beta$ Press. (http://www.library.uu.n1/digiarchief/dip/diss/01873016/inhoud.htm)

Klaassen, C.W.J.M. \& Lijnse, P.L. (1996). Interpreting students' and teachers' discourse: an underestimated problem? Journal of research in science teaching, 33. 115-134.

Mariani, M.C. \& Ogborn, J. (1991). Towards an ontology of common-sense reasoning. International journal of science education, 13. 69-85.

McCloskey, M. (1983). Intuitive physics. Scientific American, 248. 122-130.

Nagel, E. (1979). The structure of science: problems in the logic of scientific explanation. Indianapolis: Hacket Publishing Company.

Ramberg, B. (1999). The significance of charity. In: L.E. Hahn (ed.). The philosophy of Donald Davidson. Chicago: Open Court. 601-618.

Smith, J.P. III, diSessa, A.A., Roschelle, J. (1993). Misconceptions reconceived: a constructivist analysis of knowledge in transition. The journal of the learning sciences, 3. 115-163.

Westra, A., Klaassen, K. \& Lijnse, P. (2003). A new introduction for teaching-learning mechanics. Paper presented at ESERA 2003.

Whitelock, D. (1991). Investigating a model of commonsense thinking about causes of motion with 7 to 16-year-old pupils. International journal of science education, 13. 321340. 